\title{
Using the Diffusion of Innovation Theory to Explain the Degree of English Teachers' Adoption of Interactive Whiteboards in the Modern Systems School in Jordan: A Case Study
}

\author{
Mustafa Jwaifell \& Al-Mothana Gasaymeh \\ Al-Hussein Bin Talal University, Jordan
}

\begin{abstract}
This study aimed to explain the use of interactive whiteboards (IWBs) by English female teachers in Modern Systems School in Jordan. Viewed from the lens of Rogers' Diffusion of Innovation Theory, the study examined and reported teachers' use of IWB and its features that have impact on their decisions to adopt it in Modern Systems School. The study employed the qualitative case study approach. Data were collected through different ways such as semi-structured interviews, document reviews, and participatory observations. Rogers' (2003) diffusion of innovations theory was used to guide the investigation. The study concluded that the extent of teachers' use of IWB is related to their perceptions of the five major attributes: Relative advantages, compatibility, simplicity, trialability, and observability. The regular use of IWB has shifted the teachers' methodologies of teaching from traditional ways to using dialogues, open sources, and group work. The study finally recommended giving more attention to training workshops regarding how to integrate IWB into the educational process.
\end{abstract}

Keywords: Interactive white board; IWB; Diffusion of innovation theory; ICT tools; English teachers; Instructional technology.

\section{Introduction}

In the current time, the technology plays a crucial role in teaching and learning. However, "Technology alone is not the remedy to a quality education system rather that technology is useful relative to its need in achieving a learning outcome" (Kervin, Varenikina, Wrona, \& Jones, 2010, p.10 ) In educational process and instructional design, new technology should be employed in an effective way with a meaningful pedagogical role rather than just content's transmitter. E-learning has become an important methodology that is integrated in teaching and learning process in order to enhance the quality of education (Hussein, 2011).

One of the essential technologies that enhance e-learning in the classroom is the interactive white board (IWB), which can be considered as an effective tool that is used to display the content using multimedia. IWB enables the teacher to control the screen and the computer using a finger, pen, or any other tool (Gruber, 2011). By using IWB, teachers can highlight, enhance, and save educational contents along with documenting student suggestions that can be used to enhance teachers' practice, collaborative learning, and interactive training (Essig, 2011). There is a growing understanding of the requirement to align the use of technologies with proper pedagogy, particularly with the advancement of the current technologies such as IWBs within university and college settings (Miller, Glover, Averis, \& Door, 2005). Teachers use 
IWBs for different reasons. These include retaining students' attention, explaining complex concepts, facilitating teaching process, and increasing fruitful interaction among students and teachers (Jang \& Tsai, 2012).

IWBs are purchased and used extensively by educational institutions all over the world. In Jordan, most of the IWBs can be found in prestigious schools, where private schools make IWBs available as a part of their prestige and image to attract more students. The question arises whether this innovation is used to improve the quality of instruction or just for the purpose of advertising. This question can be answered by examining teachers' adoption of IWBs through the lens of diffusion of innovation theory suggested by Rogers (2003).

\section{Background of the Study}

Significant funds have been invested by Ministry of Education in Jordan to purchase new Information Communication Technologies (ICT), where there are governmental interest to integrate ICTs into the educational process. Likewise, private schools have shown great interest to the integration of the ICTs in their curricula in order to attract more and more students. IWBs are commonly used in those private schools to enhance the way of presenting content to students. In some cases, teachers were forced to use IWB in teaching and learning process regardless of their attitudes toward or satisfaction with such technology. The use of IWBs may differ from one teacher to another so that the pedagogy behind such practices.

In the current time, a few research studies have been conducted that investigated the use of IWBs within classrooms (Digregorio \& Sobel-Lojeski, 2009; Essig, 2011). Intharaksa (2009) used the diffusion of innovation theory to explain the degree of faculty's adoption of web-based instruction in a Thai university. To our best knowledge, there is no specific study in Jordan that has been conducted to investigate the use of IWBs based on the diffusion of innovation theory of Rogers (2003). However, there are some studies examining the effectiveness of IWBs on students' achievement (Abu El Einein, 2011; Hanafi, 2010). Individual teachers' adoptions and perceptions of the IWBs can be better understood through the perspective of the diffusion of innovation theory.

\section{Interactive White Boards}

Interactive whiteboards were first developed at the beginning of the 21st century (Betcher \& Lee, 2009) as a new ICT tool. IWBs have been widely used in schools and universities to provide innovative ways of displaying the educational contents in different format like animated text, colored text, shapes, pictures, images, video, and audio.

The uses of ICTs provide technology-rich classroom environments. IWBs can display content not only in static way, but also they help in showing dynamic content (Betcher \& Lee, 2009). Many functions are integrated in IWBs; one of those is storing and recalling data, where the teacher can record lessons and repeat them as much as needed. IWBs can also be used to replace traditional boards.

Despite the fact that IWBs are playing an integral role as interactive tool, teachers' attitudes toward and perceptions of IWBs are still critical factors for their successful integration. Smith, Higgins, Wall, and Miller (2005) suggested that there must be some kind of training both for 
teachers and students regarding the use of IWBs. Some teachers may face problems in setting up a classroom with IWBs due to technical obstacles (Preston \& Mowbray, 2008). IWBs can attract students' attention, but some teachers believed that IWBs may increase burden and became an over work load for them (Dang, 2011). Using IWBs to design instruction may face a number of pedagogical, educational, and technical obstacles that need to be overcome.

\section{Diffusion of Innovation Theory}

Diffusion can be defined as a "process that communicates an innovation through specific channels among the members of a social system." New innovations adoption process usually begins with a tiny number of innovators according to Rogers' Theory of Diffusion of Innovation (Robinson, 2009; Rogers, 2003). Thus, adopters of innovation can be categorized as shown in Figure 1.

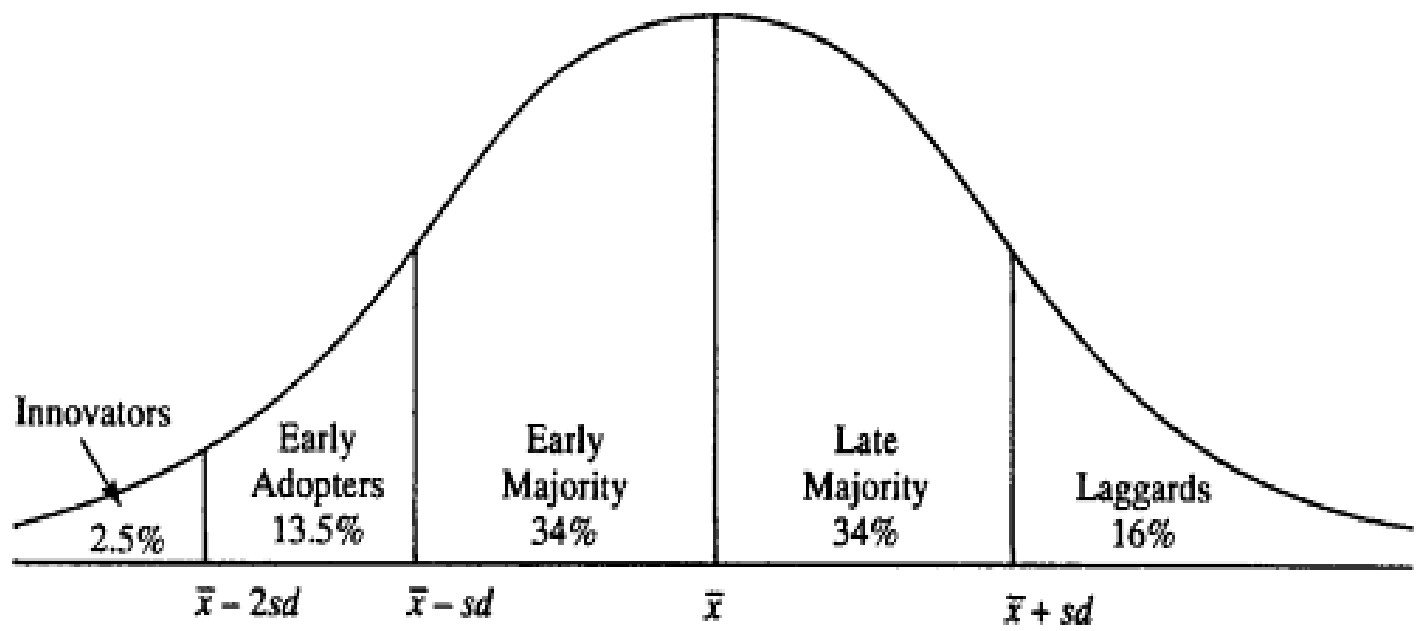

Figure 1: Adopter Categorization (Rogers, 2003, p. 281)

A population can be broken down into five different segments, based on their propensity to adopt a specific innovation: Innovators, early adopters, early majorities, late majorities and laggards.

The adoption as decision process requires the potential adopter collect information regarding the technology, examine the technology, and consider whether it provides sufficient improvement to deserve the investment of energy and time that is needed to add it to his/her range of skills (Rogers, 2003). Therefore, people tend to explore the new technology, and experience how effectively it would work in their activities before accepting or rejecting those technologies (Rogers, 2003). This theory tries to explain how an innovation, which may be about an idea, behavior, or object, is adopted among population. Diffusion of Innovations Theory offers valuable insights into the process of social change (Robinson, 2009) as the main qualities that provide a successful spread of an innovation. These include the significance of peer-to-peer conversations along with peer networks and the understanding the needs of different user segments. 
Spreading of new innovation can be achieved through considering five qualities related to the innovation from the perspective of the innovators; based on Rogers, (2003), these five qualities are:

- Relative advantage: The greater the realized relative merit of an innovation, the more quick its rate of adoption is likely to be;

- Compatibility: It refers to the degree to which an innovation is perceived as being consistent with the values, past experiences, and the needs of possible adopters;

- Simplicity and ease of use: New ideas that are simpler to understand for the potential adopter are adopted more rapidly than innovations that require the adopter to develop new skills and understandings.

- Trialability: It refers to the degree to which an innovation can be experimented with on a limited basis;

- Observable results: The easier it is for individuals to see the results of an innovation, the more likely they are to adopt it.

\section{Purpose of the Study}

The purpose of this study was to explain the use of IWBs by English female teachers in Modern Systems School in Jordan. Viewed from the lens of Rogers' diffusion of innovation, this study examined and reported teachers' use of IWBs and their perceived attributes that affect teachers' decisions to adopt IWBs at the selected school.

To achieve the main purpose of the study, research was conducted to answer the following questions:

(1) How is IWB used among English teachers at the Modern Systems School?

(2) What are the English teachers' perceptions of IWBs in the Modern Systems School?

(3) How does Rogers's (2003) major attributes of innovation explain English teachers' perceptions of IWBs at Modern Systems School?

\section{Methods}

The current study is a case study, where the primary purpose was to qualitatively examine teachers' use of IWBs and their perceptions regarding the use of this technology in the Modern Systems School in Jordan. Within the context of qualitative research paradigm, case study is one of the important approaches mentioned by Creswell (2007), which represents exploratory and descriptive research approach.

\section{Setting and Sample}

The sample of the study includes 4 teachers who are currently teaching English at the Modern Systems School in Jordan. Table 1 shows the participants' experience and majors. 
Table 1. Participants' Experience and Majors

\begin{tabular}{|c|c|l|l|}
\hline $\begin{array}{c}\text { Participant } \\
\text { code }\end{array}$ & Number of years of experience & Qualification & \multicolumn{1}{|c|}{ Major } \\
\hline Tas & 5 & Master & English literature \\
\hline Mays & 7 & Bachelor & English language and literature \\
\hline Abr & 3 & Bachelor & English language and literature \\
\hline Ram & 2 & Bachelor & English language and literature \\
\hline
\end{tabular}

The participants were female teachers teaching sixth to eighth grades. They have relatively low level of experience (between 2-7 years) in teaching. Except one, three of them hold bachelor's degree. Following the administration's approval for conducting this study, interviews with the participants took place at their offices with permission of audio recording.

\section{Instrument}

In this study, the major data gathering instrument was a semi-structured interview questions, which were designed by the researchers to collect information about the teachers' degree of use of and perceptions of IWBs in teaching. The semi-structured interview questions were validated through four referees from the department of curriculum and teaching in Al-Hussein University, where reliability depended on instrument consistency, predictability, stability, or accuracy. The researchers conducted a pre-interview with one teacher at the same school to test the interview questions. The semi-structured interview questions aimed to learn teachers' degree of use and perceptions toward IWBs in teaching based on the diffusion of innovation theory that guided the investigation. The interviews questions were the following:

- What are the advantages and disadvantages of using IWBs for instruction for you as teacher, and for your students?

- How is using IWBs for instruction compatible with your teaching philosophy?

- What are the challenges that you faced when you use IWBs during your teaching experience?

- Have you received any training in relation to the uses of IWBs (such as training sessions, workshops, online training etc.)?

- What is the extent of use of IWBs in instructional design and within classrooms (i.e. times of use, type of content you display, sources at the internet or intranet, and programs)?

- Do you carefully consider the pedagogical use of IWBs as effective tools for your students' learning?

- Do you access online material or information from the internet or intranet during classes?

- What are the factors that promote or limit the use of IWBs in teaching and learning from your perspectives? 


\section{Analysis of Data}

Data were obtained from various sources including documents (teachers' lesson preparation), observations (field exploring), and interviews. The analysis of collected data was conducted in a way to protect the confidentiality of all the participants by giving them coded names (not their real names). The interview data recorded under the permission of the participants and then transcribed into paper-based form. The researchers handed back hardcopies of the transcribed interviews to participants in order to assure the recorded words have the same meaning as the written ones.

The collected data were analyzed qualitatively, organized into binders based on their themes. Documents were compared with teachers' responses to the interview questions. The field notes were detected to know about IWBs' positions and types in classrooms. The researchers took a picture for the available IWBs. Figure 2 shows the picture of an existing IWB.

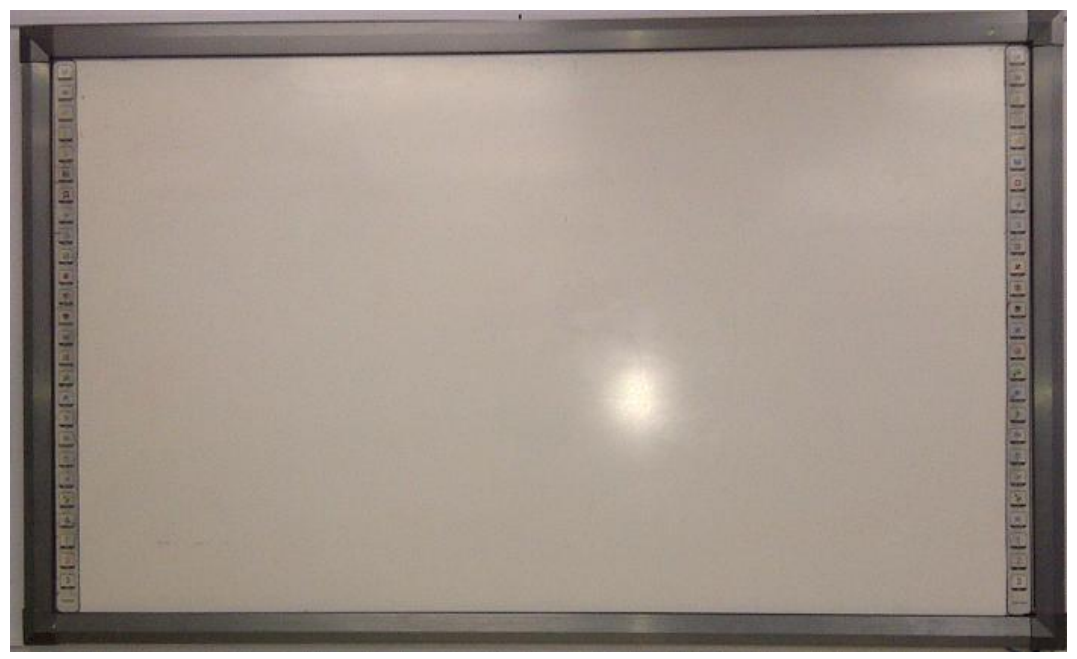

Figure 2. An IWB Available in the Classroom (Type: Ketab)

Most of the IWBs in the Modern Systems School are connected to the Internet so that teachers can easily have access to different sources on the web.

\section{Findings}

Research Question 1: How are IWBs used among English teachers at the Modern Systems School?

Regarding the first research question, a qualitative approach was employed to explore the participants' use of IWBs. They were asked to answer the following questions:

- How is using IWBs for instruction compatible with your teaching philosophy?

- What is the extent of use of IWBs in instructional design and within classrooms (i.e. times of use, type of content you display, sources at the internet or intranet, and programs)? 
- Do you carefully consider the pedagogical use of IWBs as effective tools for your students learning?

- Do you access online material or information from the internet or intranet during the classes?

All the four participants received training conducted at the school by the IWBs supplier but they have not received any training regarding the use of IWBs as an instructional tool. The extent of using IWBs was beyond the use as a general tool of displaying content to students. For instance, Mays stated that: "IWB helps teachers introduce their ideas in many different ways and it is easier to capture students' attention." The teachers confirmed that IWBs shifted the way of presenting content in an interactive way based on dialogue and open sources, while the IWB is connected to the internet. Tas indicated that the use of IWBs can be a powerful tool that helps provide auditory and visual context. She stated that: "IWB enables student to develop their oral and aural skills." The participants confirmed that they use IWBs all the time within their classes. Mays stated that: "I always use it in each class; I use it 30 minutes out of a 40 minutes class." The types of the educational content, that they used IWB to present, vary from one teacher to another. However, they all use IWBs to convert abstract content into a visual one as they mentioned. The instructional strategies that they used can be categorized into three types which are dialogue, open sources (while the IWB is connected to the internet), and group work. All the participants use different types of programs to display the content such as PowerPoint presentations, authoring systems (Flash), videos, text; animated and highlighted text; pictures, and interactive programs.

Summary of Answers to Question 1: All the participants use IWBs in all classes that they teach. IWBs shifted instructional strategies that they use from discussion into dialogue, open sources, and group work. They display the content in different media that convert abstract contents into interactive ones. They used popular programs like PowerPoint and Flash. It is obvious that the teachers consider IWB as an appropriate tool to gain students' attention. The use of the Internet as an open source is still limited, where IWB are most used to display the content of different media.

Research Question 2: What are the English teachers' perceptions of IWBs in the Modern Systems School?

Regarding the second research question, a qualitative approach was employed to explore the participants' perceptions of IWBs. They were asked the following questions:

- What are the advantages and disadvantages of using IWBs for instruction for you as a teacher and for your students?

- What are the challenges that you face when using IWBs in during teaching?

- Have you received any training in relation to the uses of IWBs (such as training sessions, workshops, online training etc.)?

- What are the factors that promote or limit the use of IWBs from your perspectives?

None of the participants confirmed that IWBs have disadvantages; only Abr and Mays pointed to the issue related to some technical problems that she faced during her use of IWB. Abr 
made an interesting declaration: "Sometimes, students know how to use the board better than me." It can be concluded form this declaration that the training about how to use IWB that Abr received was not enough. In addition, Abr's little experience can clarify her declaration where her experience at the Modern Systems School was only three years, whereas the students of this school can be considered as high social class students who have experience with different technologies such as computer and Internet. The supplier training focused on how to operate IWB rather than how to use it in a pedagogical manner. Therefore, all the participants perceived IWB as a display tool rather than as being an educational tool that requires special considerations when designing instruction with. However, the participants have had gradually discovered some pedagogical applications of the IWB through their experience with the this technology in this school.

All the participants agreed that IWB has many advantages both teachers and students. The reported advantages were related to the facilitation of the educational process in terms of gaining students' attention displaying the content in different forms, and saving teachers' as well as students' time and effort. None of the participants has mentioned any disadvantage of IWBs. However, the participants have reported the need to practice using IWB before the beginning of the class as Tas stated: "If I am not well prepared before class on how to integrate IWB, it will certainly turn to be a burden trying to employ it during class, which takes a lot of time and effort."

The participants indicated that the current era of technology demands the use of IWBs as, Mays put it: "Everything is based on technology nowadays and students are attracted to anything related to technology." Abr also mentioned that: "In our school, we believe that this is the age of technology, which is the driving force behind the need to implement different technologies such as IWB in our classes."

Considering the factors that limit the use of IWBs, three participants considered the lack knowledge of IWBs' tools and the lack of technical support are the major barriers that limit the use of IWBs. Tas said that: "I am not completely aware of the tools provided by IWBs. Technical problems that may occur during the use of IWBs in the class would waste the time of the class. Therefore, teachers sometimes forget about employing it in class and they just use it as a white board."

Summary of Answers to Question 2: All the participants believed that IWBs can save time and effort as an advantage of using IWBs. The reported disadvantages were related to lack of training and technical support. From the perspective of the participants, the only challenge of the use of IWBs was related to the knowledge about IWBs and the need to technical support. The main factors that promote the use of IWBS were related to the technology itself, where participants believed that IWB provides several advantages as display tool. The teachers perceived IWB as a helpful tool to communicate with their students through the content in term of displaying interactive educational content during their classes so that they think that IWBs are required in the current era of technology.

\section{Research Question 3: How do Rogers's (2003) attributes of innovation explain English teachers' perceptions of IWBs at the Modern Systems School?}

Regarding the third research question, a qualitative approach was employed to explore the participants' use of IWB and the factors that might affect their decision to use it. The semi- 
structure interview questions focused on the English teachers' at the Modern Systems School perceptions of the IWB based on the five major attributes of innovation that had affect an individual's decision. Rogers's (2003) attributes of innovation in this context include relative advantage, compatibility, complexity, trialability, and observability.

Relative advantage: The strongest predictor of an innovation's rate of adoption is its perceived relative advantages. It refers to the benefits that a person would consider when he/she is deciding to adopt the innovation. The participants pointed to the advantages of IWB, which they were related to the facilitation of the educational process in terms of gaining students' attention, displaying the content in different forms, and saving teachers as well as students' time and effort.

Compatibility: As indicated earlier, "it is the degree to which an innovation is perceived as consistent with the existing values, past experiences, and need of potential adopters" (Rogers, 2003, p.266). The process of adopting an innovation can be accelerated if the individual feels that this new innovation is compatible with their needs and experiences. All the participants felt that IWB is a powerful tool to help teacher saving time and effort. Regarding the teachers' perceived values and beliefs, they all had positive values/beliefs toward the implementation of the IWB in the educational process, particularly in the current era of technology. More importantly, they pointed that IWBs are one of those tools which shifted traditional classes to interactive ones.

Complexity: "It refers to is the degree to which is perceived as relatively difficult to understand and to use" (Rogers, 2003; p.266). All the participants find IWB to be easy to use. For instance, Abr noted that sometimes, her students know how to use IWB better than her, which reflects that Abr lacks experience on how to use IWB even though it is easy to use, where the students can know how to operate it without training.

Trailability: This attribute explains the degree to which an innovation may be experimented on a limited base (Rogers, 2003; p.266). The participants were not forced to use IWB for their teaching, although they use it all the time in every class. For instance, Mays pointed that that she used it $\mathbf{3 0}$ minutes out of the $\mathbf{4 0}$ minutes class. Participants had the opportunity to try the IWB and they were free to continue or discontinue using it.

Observability: This concept refers to the degree to which the results of an innovation are visible to others (Rogers, 2003; p.266). Participants' responses to the interview questions showed that they have the chance to examine the IWB in their educational practices and to take advantages of it.

Summary of Answers to Question 3: The five characteristics of IWB, as mentioned in Rogers's (2003) theory, have played a crucial role in motivating all the four participant teachers to use IWB in their teaching.

\section{Conclusions and Recommendations}

The present study revealed significant results on how teachers are using interactive white boards. All participant teachers accepted IWBs' use and they believed that this technology provides several benefits for teaching and learning. The participants did not have any training on how to integrate IWBs with respect to pedagogical concepts and learning theories. The five 
characteristics of innovation mentioned in Rogers' (2003) theory on diffusion of innovations have played important roles in motivating or encouraging the participant teachers to use IWB during their teaching.

It can be safely concluded that relative advantages, compatibility, simplicity, trialability, and observability of an innovation accounted for English language teachers' adoption of IWBs in the Modern Systems School in Jordan. This can be also valid for teachers in other schools. As many training workshops are conducted in every semester with the teachers at the Modern Systems School, one should expect, according to the diffusion of innovation theory that IWBS will have more adopters in the future.

Based on the results of this study and subsequent conclusions, the researchers' suggestions for the Modern Systems School will be about two major aspects: The first one is to train teachers to gain instructional design skills based on the existence of IWBs. The second one is to provide more technical support by employing one technician for each department. For further studies, the researchers recommend a larger-scale replication study with a larger sample sizes or more participants embracing other schools and/or another disciplines. A quantitative/mixed-method studies should be conducted with extensive samples of students to explore the impact of using IWBs on the students' performance and attitudes.

\section{References}

Abu El Einein, R. (2011). The effect of using the smart board on student's achievement in learning Arabic at the beginner's level for non-native speakers (Unpublished master's thesis). Department of Psychological and Educational Sciences, Faculty of Arts and Education, The Arabic Academy in Denmark.

Betcher, C. \& Lee, M. (2009) The interactive whiteboard revolution: Teaching with IWBs. Victoria, Australia: Acer. Available at: http://schoolnet.org.za/CoL/ACE/course/ classroom/documents/iwb_revolution.pdf

Creswell, J. W. (2007). Qualitative inquiry and research design: Choosing among five traditions (2nd ed.). Thousand Oaks, CA: Sage.

Dang, X. T. (2011). Factors influencing teachers' use of ICT in language teaching: A case study of Hanoi University, Vietnam. International Conference on ICT for Language Learning. CITY?Australia. Retrieved on 21 December 2012 from http://www.pixel-online.org/ ICT4LL2011/common/download/Paper_pdf/SLA51-478-FP-Dang-ICT4LL2011.pdf

Digregorio, P. \& Sobel-Lojeski, K. (2009). The effects of interactive whiteboards (IWBs) on student performance and learning: A literature review. Journal of Educational Technology Systems. 38(3), 255-312.

Essig, D. (2011). A case study of interactive whiteboard professional development for elementary mathematics teachers (Unpublished doctoral dissertation). Walden University. Minneapolis, Minnesota.

Glover, D., Miller, D., \& Averis, D. (2003, September). The impact of interactive whiteboards on classroom practice: Examples drawn from the teaching of mathematics in secondary schools in England. Proceedings of the International Conference: The Decidable and the Undecidable in Mathematics Education. Brno, Czech Republic. Available at: http://math.unipa.it/ grim/21_project/21_brno03_Miller-Averis.pdf 
Gruber, B. (2011). A case study of an interactive whiteboard district-wide technology initiative into middle school classrooms (Unpublished doctoral dissertation). George Mason University. Fairfax, VA.

Hanafi, A. (2010). The effectiveness of a smart-board based program in developing some electronic teaching skills of teacher students in mathematics section (Unpublished master's thesis). Almenofeyya University. Shbeen El-coom, Egypt.

Hussein, H. B. (2011). Attitudes of Saudi universities' faculty members towards using learning management system (JUSUR). Turkish Online Journal of Educational Technology, 10(2), 43-53.

Intharaksa, U. (2009). Using diffusion of innovation theory to explain the degree of faculty adoption of Web-based instruction in a Thai university (Unpublished doctoral dissertation). Oklahoma State University. Available at: http://139.78.48.197/utils/ getfile/collection/Dissert/id/ 72454/filename/73145.pdf

Jang, S. J. \& Tsai, M. F. (2012). Reasons for using or not using interactive whiteboards: Perspectives of Taiwanese elementary mathematics and science teachers. Australian Journal of Educational Technology, 28(8), 1451-1465.

Kervin, L. K., Verenikina, I., Wrona, K., \& Jones, P. T. (2010). Interactive whiteboards: Interactivity, activity and literacy teaching. In J. Herrington \& B. Hunter (Eds.), Proceedings of World Conference on Educational Multimedia, Hypermedia and Telecommunications (pp. 2605-2614). Virginia, USA: AACE. Available at: http://ro.uow.edu.au/cgi/viewcontent.cgi?article=1122\&context=edupapers

Miller, D. J., Glover, D., Averis, D., \& Door, V. (2005). From technology to professional development: How can the use of an interactive whiteboard in initial teacher education change the nature of teaching and learning in secondary mathematics and modern languages? London: Training and Development Agency. Retrieved on 24 December 2012 from http://webarchive.nationalarchives.gov.uk/20101021152907/http:/www. ttrb.ac.uk/attachments/0d65acf3-488a-4fca-8536-918d6dafd694.pdf

Preston, C. \& Mowbray, L. (2008). Use of SMART boards for teaching, learning and assessment in kindergarten science. Teaching Science Journal, 54(2), 50-54.

Robinson, L. (2009). A summary of diffusion of innovations. Retrieved 25 December 2012 from http://www. enablingchange.com.au/Summary_Diffusion_Theory.pdf

Rogers, E. M. (1986) Models of knowledge transfer: Critical Perspectives. In G. M. Beal, W. Dissanayake, \& S. Konoshima (Eds.), Knowledge generation, exchange and utilization (pp.37-60).. Boulder, CO: Westview. Retrieved on 19 October 2012 from https:// studieninteressierte.unihohenheim.de/uploads/tx_uniscripts/25720/A7020_KIM_2011. pdf

Rogers, E. M. (2003). Diffusion of innovations ( $5^{\text {th }}$ ed.). New York: Free Press. Retrieved on 19 October 2012 from http://books.google.com.sa/books?id=9U1K5LjUOwEC\&lpg=PP1\&dq $=$ Diffusion\%20of\%20Innovations \&pg=PP1\#v=onepage \&q\&f=false

Smith, H. J., Higgins, S., Wall, K., \& Miller, J. (2005). Interactive whiteboards: Boon or bandwagon? A critical review of the literature. Journal of Computer Assisted Learning, 21, 91-101. Retrieved on 17 November 2012 from http:// edtech2.boisestate.edu/ spechtp/551/IWB_Boon_Bandwagon.pdf 
Correspondence: Mustafa Jwaifell, Ph.D., Instructional Technology, Department of Curriculum and Instruction, Al-Hussein Bin Talal University, Ma'an, Jordan 